\title{
High Capacity of the Metastatic Breast Tumor Cells in Sphere Formation: Clue for Chemoresistance in Triple- Negative Breast Cancer
}

\author{
(1) Mohammad Kamalabadi FARAHANi'
}

'Department of Tissue Engineering, School of Medicine, Shahroud University of Medical Sciences, Shahroud-Iran

\begin{abstract}
OBJECTIVE
Metastasis is a major cause of cancer-related death in Triple-Negative Breast Cancer (TNBC). In TNBC, there is a significant correlation between metastasis and chemoresistance. Cancer relapse and metastasis are associated with the part of cancer cells with stem cell properties. These cancer stem cells are resistant to current cancer treatments. Due to their resistant nature, a significant relationship exists between the amount of cancer stem cells and chemoresistance. To our knowledge, to date, no comparative study was conducted on the number of these cells in metastatic loci vs. primary tumor site.
\end{abstract}

\section{METHODS}

In the present study, after developing a metastatic animal model of TNBC, metastatic and primary tumor cells were extracted from the lung and primary tumor of cancerous mice, respectively. In the next step, the sphere formation ability as a reliable in vitro assay to assess the presence and self-renewal ability of CSCs, in metastatic and primary tumor cells was evaluated separately.

\section{RESULTS}

The results showed that sphere formation ability, and consequently the population of cancer stem cells among metastatic tumor cells was significantly higher.

\section{CONCLUSION}

A higher percent of CSCs in lung metastatic site, compared with the primary tumor site, can partly explain the reasons for the chemoresistance and relapse in metastatic TNBC.

Keywords: Cancer stem cells; metastasis; sphere formation; triple-negative breast cancer.

Copyright $\odot$ 2020, Turkish Society for Radiation Oncology

\section{Introduction}

Breast cancer is the most common cancer in women worldwide.[1] Triple-negative breast cancer (TNBC) is the most aggressive and invasive type of breast cancer with poor prognosis. Combination chemotherapy is the standard treatment for patients with TNBC.[2] Targeted treatments essentially improve the patient's outcome for some types of breast cancer. However, in particular, TNBC has faced some potential challenges. The recurrence and metastasis of TNBC due to chemoresis- tance takes place in up to $70 \%$ of the patients.[3]

Metastases account for $90 \%$ of human cancer deaths. In cancer, metastasis and resistance to chemotherapy are linked phenomena.[4] Especially in breast cancer, metastasis is a major cause of fatality. Bone, lung and liver are the main sites of metastases in this disease.[5] In the metastasis process, metastatic tumor cells become chemo and radioresistance, which may ultimately lead to a failure of the common therapeutic approach. The molecular mechanisms that lead to therapeutic resistance are diverse and are still incompletely

Dr. Mohammad Kamalabadi FARAHAN

Department of Tissue Engineering,

School of Medicine,

Shahroud University of Medical Sciences,

Shahroud-Iran

E-mail:kamalabadi@shmu.ac.ir 
understood. [6] Identification of these specific features could be useful in the designing of new therapies. In this regard, many studies are ongoing.[7-9]

Extensive cancer research has clarified the existence of a rare subpopulation of stem cells between heterogeneous populations of cancer cells in recent decades. These cells are known as the cancer stem cells or cancerinitiating cells characterized by the presence of surface biomarkers, multi-drug resistance pumps and deregulated self-renewal pathway. They have a decisive role in stimulating cancer cells leading to tumorigenesis and its advanced metastasis.[10] In breast cancer, many studies demonstrate the existence of breast cancer stem cells (BCSCs). They emphasized that BCSCs are have a fundamental role in tumour progression, metastasis and resistance to current cancer treatment.[11,12]

It has been demonstrated that CSCs have the ability to form spheres in vitro when grown in special culture conditions. [13] Such spheres that allow the growth and propagation of CSCs applied as a standard experimental test for evaluating the potential of stemness in cancer cells and is the best tool for characterizing cancer stem cells.[14]

Several authors have emphasized on the pivotal role of the CSCs as the active source of metastatic spread; however, analysis of the role of CSCs in metastasis has been mainly conceptual and speculative.[15] The presence and quantity of CSCs in metastatic loci were hence the focus of this study. We created a lung metastatic mice model of TNBC. Primary and metastatic tumor cells were extracted from cancerous mice and the number of CSCs was compared between these cells.

\section{Materials and Methods}

\section{Cell Culture}

4T1 cell line was obtained from the cell bank of the Pasteur Institute of Iran (C604). The cells were cultured in high glucose Dulbecco's Modified Eagle's Medium (DMEM) containing 10\% FBS (fetal bovine serum) and $2 \%$ Penicillin-Streptomycin (all from Gibco, USA) in a humidified atmosphere of $5 \% \mathrm{CO}_{2}$ at $37^{\circ} \mathrm{C}$.

\section{Induction of Syngeneic Animal Model of Breast Cancer}

Female BALB/c mice weighing 20 to 25 gram obtained from Royan Institute (Iran). The animals were housed in cages at 12-h photoperiod while they had free access to food and water. All animal experiments were in compliance with the relevant laws, and this study was approved by the Ethics Committee of Tehran
University of Medical Sciences (registration number: IR.TUMS. REC.1394.1439). 4T1 cells were subcutaneously injected to the flank (or the right hind limb) of the mice (105 cells suspended in $100 \mu \mathrm{L}$ PBS) using an insulin syringe with a $32 \mathrm{G}$ needle. The mice were monitored daily for appearance and behavior characteristics.

\section{Lung Metastatic and Primary Breast Tumor Cell Ex- traction}

TPrimary and metastatic tumor cells were extracted as previously described.[16] Briefly, the primary tumor and lung of cancerous mice were excised after 35 days of tumor induction in mice, and surface blood was removed by rinsing it in PBS. After mincing with scissors, fragments were placed to a $50 \mathrm{ml}$ conical tube. For enzymatic digestion, primary tumor and the lungs were digested in $10 \mathrm{mg} / \mathrm{ml}$ collagenase type IV at $37^{\circ} \mathrm{C}$ for $75 \mathrm{~min}$ on a platform rocker. All enzymes were purchased from Sigma (St Louis, MO, USA). The digested organ were filtered through 70-um cell strainers and washed with PBS. In the next step, washed cells were resuspended in medium containing 10\% FBS, $100 \mathrm{U} / \mathrm{ml}$ Penicillin, and $100 \mathrm{ug} / \mathrm{ml}$ Streptomycin (all from Gibco, USA). Ultimately, the cells were cultured at $37^{\circ} \mathrm{C}$ in $5 \% \mathrm{CO}_{2}$.

\section{Sphere Formation Ability}

Heterogeneous population of primary and lung metastatic tumor cells was separately cultured in DMEM containing 10\% FBS, $100 \mathrm{U} / \mathrm{ml}$ Penicillin, and $100 \mathrm{ug} / \mathrm{ml}$ Streptomycin (all from Gibco, USA) at $37^{\circ} \mathrm{C}$ in $5 \% \mathrm{CO}_{2}$. For Sphere formation, cells were seeded at $2.5 \times 104$ cells in a petri dish in DMEM supplemented with $10 \%$ FBS. After $24 \mathrm{~h}$, cell culture media replaced with fresh medium comprised of DMEM supplemented with $2 \%$ FBS. Again, after $72 \mathrm{~h}$, cell culture media replaced with fresh medium comprised of DMEM supplemented with $1 \%$ FBS. Primary $/ 1^{\circ}$ and secondary $/ 2^{\circ}$ mammosphere formation was achieved after eight days. The sphere formation index was determined by two independent investigators by counting the sphere formed in 10 high power fields per petri dish.

\section{Statistical Analysis}

Results are expressed as the mean \pm standard deviation. Data were analyzed with GraphPad Prism statistical software 6.0 (GraphPad Software, La Jolla, CA, USA) using Paired Samples t-test. $\mathrm{P}<0.05$ was considered statistically significant. 


\section{Results}

\section{Primary and Metastatic Tumor Cells Extraction}

Metastatic animal model of triple-negative breast cancer was generated after 35 days following tumor induction in Balb/c mice (Fig. 1a). When injected into BALB/c mice, $4 \mathrm{~T} 1$ spontaneously produces highly metastatic tumors that can metastasize to the lung while the primary tumor is growing in situ. The primary tumor does not have to be removed to induce metastatic growth. 4T1 H \& E staining and pathological confirmation were performed on tumor tissues (Fig. 1b). We properly extracted primary and lung metastatic tumor cells from subcutaneous primary tumor and lung of cancerous mice, respectively (Fig. 1b, 1c). The metastatic tumor cells in the lung, after primary isolation, form colonies in the culture medium. Due to the high rate of growth and proliferation, the tumor cells in these colonies are purified after several passages. These tumor cells are called lung metastatic tumor cells (Fig. 1c3) while tumor cells that are obtained in the same way, from the original tissue of the tumor, are primary tumor cells (Fig. 1b3).

\section{Higher Capacity of Metastatic Tumor Cells in Sphere Formation}

After eight days of culturing primary and metastatic tumor cells in sphere forming media, results indicated that metastatic tumor cell have greater ability in sphere formation. As shown in Figure 2, metastatic tumor cell sphere formation ability was higher and greater than primary tumor cell concerning number and size, respectively.

\section{Discussion}

Current research in TNBC, that is aggressive subtype of breast cancer, is focused on a greater understanding of the response and resistance to treatment.[17] Despite a variety of available approaches for the treatment of metastatic TNBC, the survival rate of patients remains very low. In TNBC, metastasis and chemo-resistance are the most common causes of treatment failure. Elucidating the underlying mechanisms is crucial for developing new therapeutic strategies.[18,19]

In the present study, after extraction of primary and metastatic tumor cells from mouse model of TNBC, we analyzed sphere formation ability in these cells. We determined that sphere formation ability as a key cancer stem cells property in metastatic tumor cells is significantly higher than primary tumor cells. Accordingly, we concluded that percent of CSCs population

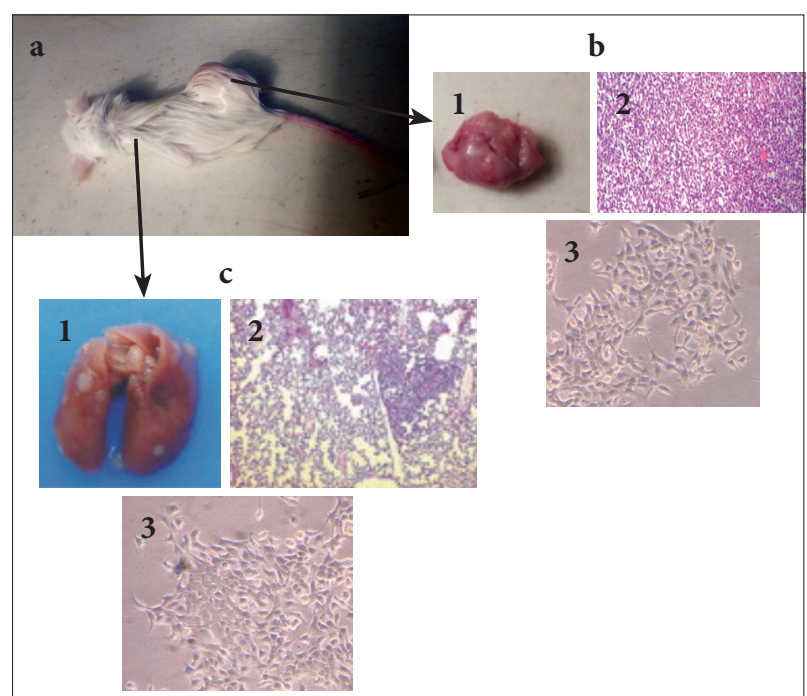

Fig. 1. Primary and lung metastatic tumor cells extraction. (a) Metastatic animal model of triple negative breast cancer was generated after 35 days of tumor induction in Balb/c mice. (b) Primary tumor isolation, $\mathrm{H} \& \mathrm{E}$ staining and primary tumor cell extraction were performed on primary tumor tissues. (c) Lung metastatic tumor isolation, $\mathrm{H} \& \mathrm{E}$ staining and metastatic tumor cell extraction were performed on the lung of cancerous mice.

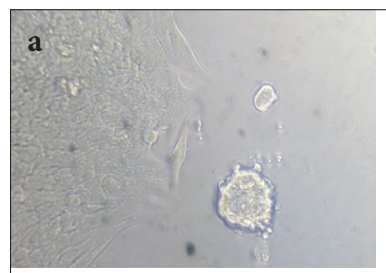

Sphere formation in primary tumor cells

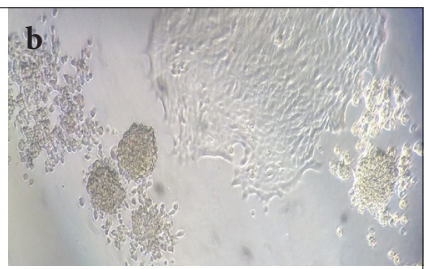

Sphere formation in lung metastatic tumor cells c

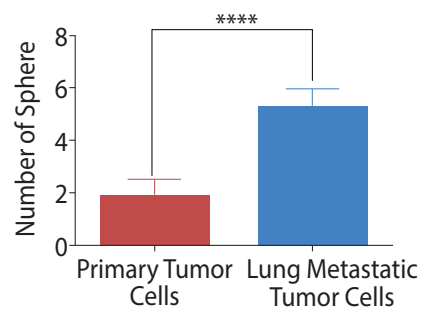

Fig. 2. Higher capacity of lung metastatic breast tumor cells in sphere formation. $a$ and $b$, Induction of sphere formation in primary and metastatic tumor cells after serum starvation in culturing media. c. Sphere formation capability was significantly higher in lung metastatic tumor cells. All results were expressed as mean \pm SD from at least three independent experiments analyzed by unpaired t-test. ${ }^{* * *} \mathrm{P}<0.0001$. 
in metastatic loci is higher than primary tumor. Then, these CSCs can be responsible for chemoresistance and relapse in TNBC.

Hierarchical potential of CSCs to sustain self-renewal along with constructing daughter cells that result in the establishment of bulk tumor cells, while keeping a self-replicating potential.[20] BCSCs are increasingly thought to play a major role in breast cancer growth and the formation of metastases. Sphere forming ability of Breast CSCs have been demonstrated in tumor cells isolated from pleural effusions of breast cancer patients. These cells were tumorigenic when transplanted into SCID mice.[21] Flow cytometric analysis indicated that BCSCs expressed CD44 but had low or undetectable levels of CD24 and were lineage negative (CD44+CD24-/low/lin-).[22]

Survey of researches indicated that CSCs make up a small minority of most tumors, while in a small number of tumors (for example, melanoma), they may comprise up to $25 \%$ of the total mass.[23] A review of the resources revealed that to date no comparative study has been performed on the number of CSCs between the primary tumor and the metastatic site. In our work, higher percent of BCSCs have been recognized in metastatic loci compared with the primary tumor. Clayton et al.and Alvi et al.[24,25] in two separate research isolated cancer stem-like cells from mouse and human mammary gland tissue, respectively.In an interesting animal research on mice, higher percentages of CSCs have been identified in hyperplastic mammary glands compared to the wildtype control,[26] which clarified that the percentage of CSCs increases during breast cancer development and spread.[27]

In conclusion, our study, to our knowledge, for the first time, shows that in comparison with the primary tumor, a higher percentage of cancer stem cell is present in the metastatic site, which could be one of the main causes of resistance to chemotherapy observed in metastatic breast cancer. By targeting these cancer stem cells, we can overcome these resistance and preventing recurrences of the disease in patients with metastatic breast cancer.

Acknowledgments: We want to especially thank Dr. Mohammad Vasei for his practical advising and helpful information about metastatic breast cancer.

Peer-review: Externally peer-reviewed.

Conflict of Interest: The author declares that they have no competing interests.

Ethics Committee Approval: This study was approved by the Ethics Committee of Shahroud University of Medical Sciences (registration number: IR.SHMU.REC.1398.109).

Financial Support: This work was supported by a grant from the Shahroud University of Medical Sciences (SHMU) Grant No 9886.

\section{References}

1. Siegel RL, Miller KD, Jemal A. Cancer statistics, 2016. CA Cancer J Clin 2016;66(1):7-30.

2. Yao H, He G, Yan S, Chen C, Song L, Rosol TJ, et al. Triple-negative breast cancer: is there a treatment on the horizon? Oncotarget 2017;8(1):1913-24.

3. Isakoff SJ. Triple-negative breast cancer: role of specific chemotherapy agents. Cancer J 2010;16(1):53-61.

4. Acharyya S, Oskarsson T, Vanharanta S, Malladi S, Kim J, Morris PG, et al. A CXCL1 paracrine network links cancer chemoresistance and metastasis. Cell 2012;150(1):165-78.

5. Gonzalez-Angulo AM, Morales-Vasquez F, Hortobagyi GN. Overview of resistance to systemic therapy in patients with breast cancer. Adv Exp Med Biol 2007;608:1-22.

6. Piccart MJ, Wood WC, Hung CM, Solin LJ, Cardoso F. Breast Cancer Management and Molecular Medicine. Springer Science \& Business Media; 2007.

7. Lujambio A, Calin GA, Villanueva A, Ropero S, Sánchez-Céspedes M, Blanco D, et al. A microRNA DNA methylation signature for human cancer metastasis. Proc Natl Acad Sci U S A 2008;105(36):13556-61.

8. Ventura A, Jacks T. MicroRNAs and cancer: short RNAs go a long way. Cell 2009;136(4):586-91.

9. Cameron MD, Schmidt EE, Kerkvliet N, Nadkarni KV, Morris VL, Groom AC, et al. Temporal progression of metastasis in lung: cell survival, dormancy, and location dependence of metastatic inefficiency. Cancer Res 2000;60(9):2541-6.

10. Borah A, Raveendran S, Rochani A, Maekawa T, Kumar DS. Targeting self-renewal pathways in cancer stem cells: clinical implications for cancer therapy. Oncogenesis 2015;4(11):177.

11. Lin Y, Zhong Y, Guan H, Zhang X, Sun Q. CD44+/ CD24- phenotype contributes to malignant relapse following surgical resection and chemotherapy in patients with invasive ductal carcinoma. J Exp Clin Cancer Res 2012;31(1):59.

12. Fillmore CM, Kuperwasser C. Human breast cancer cell lines contain stem-like cells that self-renew, give rise to phenotypically diverse progeny and survive chemotherapy. Breast Cancer Res 2008;10(2):R25.

13. Morrison BJ, Steel JC, Morris JC. Sphere culture of murine lung cancer cell lines are enriched with cancer initiating cells. PLoS One 2012;7(11):49752. 
14. Amaral RLF, Miranda M, Marcato PD, Swiech K. Comparative Analysis of 3D Bladder Tumor Spheroids Obtained by Forced Floating and Hanging Drop Methods for Drug Screening. Front Physiol 2017;8:605.

15. Velasco-Velázquez MA, Popov VM, Lisanti MP, Pestell RG. The role of breast cancer stem cells in metastasis and therapeutic implications. Am J Pathol 2011;179(1):2-11.

16. Kamalabadi-Farahani M, H Najafabadi MR, Jabbarpour Z. Apoptotic Resistance of Metastatic Tumor Cells in Triple Negative Breast Cancer: Roles of Death Receptor-5. Asian Pac J Cancer Prev 2019;20(6):1743-48.

17. Haffty BG, Yang Q, Reiss M, Kearney T, Higgins SA, Weidhaas J, et al. Locoregional relapse and distant metastasis in conservatively managed triple negative early-stage breast cancer. J Clin Oncol 2006;24(36):5652-7.

18. Rivera E, Gomez H. Chemotherapy resistance in metastatic breast cancer: the evolving role of ixabepilone. Breast Cancer Res 2010;12 Suppl 2(Suppl 2):S2.

19. Davuluri G, Schiemann WP, Plow EF, Sossey-Alaoui K. Loss of WAVE3 sensitizes triple-negative breast cancers to chemotherapeutics by inhibiting the STAT-HIF-1 $\alpha$-mediated angiogenesis. JAKSTAT 2015;3(4):e1009276.

20. O’Brien CA, Kreso A, Jamieson CH. Cancer stem cells and self-renewal. Clin Cancer Res 2010;16(12):3113-20.
21. Grimshaw MJ, Cooper L, Papazisis K, Coleman JA, Bohnenkamp HR, Chiapero-Stanke L, et al. Mammosphere culture of metastatic breast cancer cells enriches for tumorigenic breast cancer cells. Breast Cancer Res 2008;10(3):R52.

22. Al-Hajj M, Wicha MS, Benito-Hernandez A, Morrison SJ, Clarke MF. Prospective identification of tumorigenic breast cancer cells. Proc Natl Acad Sci U S A 2003;100(7):3983-8.

23. Shackleton M, Quintana E, Fearon ER, Morrison SJ. Heterogeneity in cancer: cancer stem cells versus clonal evolution. Cell 2009;138(5):822-9.

24. Clayton H, Titley I, Vivanco Md. Growth and differentiation of progenitor/stem cells derived from the human mammary gland. Exp Cell Res 2004;297(2):444-60.

25. Alvi AJ, Clayton H, Joshi C, Enver T, Ashworth A, Vivanco $\mathrm{Md}$, et al. Functional and molecular characterisation of mammary side population cells. Breast Cancer Res 2003;5(1):R1-8.

26. Liu BY, McDermott SP, Khwaja SS, Alexander CM. The transforming activity of Wnt effectors correlates with their ability to induce the accumulation of mammary progenitor cells. Proc Natl Acad Sci U S A 2004;101(12):4158-63.

27. Britton KM, Kirby JA, Lennard TW, Meeson AP. Cancer stem cells and side population cells in breast cancer and metastasis. Cancers (Basel) 2011;3(2):2106-30. 